\title{
SOME REMARKS ON THE SYSTEMATICAL VALUE OF THE MALE HYPOPYGIUM IN FUNGIVORIDAE
}

\author{
BY \\ G. BARENDRECHT \\ Zoological Laboratory, Amsterdam
}

In spite of the many discussions on this subject, both in literature and meetings of entomological societies, a considerable controversy exists between those entomologists who, for determination, readily resort to a comparison of the hypopygia, this being too often the only part of the insect of fering satisfactory species characters, and those who consider this practice beneath the dignity of scientific entomology.

As it happened that the writer in the course of several years had to do much work on Fungivoridae, he had ample opportunity to become familiar with this problem.

It might be of some irierest, therefore, to put forward some remarks to which the study of the hypopygia of fungus gnats gives rise, these being supplementary to a paper published this year in the "Tijdschrift voor Entomologie".

First of all it should be stated that in this particular case the examination of the hypopygium offers little difficulty. Generally the hypopygium can be prepared in a very simple way, while some species even show the specific characters without any preparation.

Usually some minutes' boiling in diluted caustic potash sufficed to remove every trace of desiccation and shrivelling. Then the hypopygia were transferred through water and $96 \%$ alcohol into Venetian turpentine and mounted in the usual way between two small pieces of coverglass, so that they might be examined from either side.

Regarding the preparations thus treated, the chief argument of the adversaries of hypopygium study, viz.; the very dissimilar aspect of the organ in different positions, was done away with. For, in nearly all genera this treatment made the hypopygia lie on their ventral or dorsal side, only a slight movement round a transverse axis being possible. To be sure, in some genera the hypopygium tends to take a position on one side, but this is either not inconvenient in these special cases or can be prevented by the use of very thick turpentine. Of course, this simple method will not do in genera like Allodia, in which a more elaborate dissection is indispensable, the hypopygium being too complicated to be depicted in one figure.

It seems to the writer of the utmost importance, however, that with the 
description of Fungivoridae, there should always be included an exact dorsal and ventral view of the whole hypopygium. The drawback that in such figures several details are absent is balanced by the fact that they represent the organ in a position which may be repeated by every other investigator. For mere systematical purposes such standardized drawings are of greater value than many complete representations of parts.

The possibility and desirability of using the organs in question for systematical purposes in the family of the fungus gnats is determined by two factors, viz., the presence and constaney of specific characters in the hypopygium itself and the possibility or impossibility of obtaining such characters by the study of other body parts. As a matter of fact in the large genera like Fungivora, Rhymosia, Exechia, etc., this latter possibility exists only to a very limited degree.

Certainly the wing veins, the bristles of the thorax and legs, and the number of antennal segments provide most valuable characters for separating the genera, and groups of species within the genera. But for the rest they are often quite insufficient. As to the colour characters, these $I$ found for the greater part almost useless, the prepared and dried insects showing a high degree of variability. Without being quite sure I am fairly convinced that this is largely due to post mortem alterations. It may be that the colour of the living insect has been influenced by low temperature, specimens reared from mushrooms later in the year (Nov.-Dec.) generally being darker than the species usually is. But there can exist hardly any doubt as to the fading of the wing spots in older specimens of the collection. This made determination with Landrock's tables often impossible, the little spot in $\mathrm{Cu}$, for instance, being never visible in such material.

Still more troublesome is the variability shown to a certain degree by the wing veins and the bristles.

The variability of the wing veins is best illustrated by the two Bolitophila species hybrida Meig. and pseudohybrida Landr. Landrock lays much stress on the presence or absence of $t_{p}$, this cross vein being, according to him, always present in hybrida. In the Bolitophila material examined by the writer, however, there were quite a number of specimens which, although showing the other characters of hybrida (in this special case the female ovipositor is of more use than the male hypopygium) lacked the cross vein $t_{p}$. This character should be used, therefore, with some reserve.

Also the point at which $\mathrm{c}$ ends and to which great systematical importance is generally assigned, may give rise to difficulties, especially in the genera Zelmira and Coelosia, as I have shown in my former paper.

In the genus Fungivora much use is made of the chaetotaxis of the middle tibiae. It appeared, however, that at least in the species cingulum Meig. and luctuosa Meig. the bristles of the middle tibiae are subject to a considerable variability, and the use of this character is rendered still more precarious by the fact that it is often coupled with asymmetry. 
This insufficiency of the "other" characters appears perhaps most clearly from an examination of tables such as are found in the publications of Edwards and Landrock. Again and again the line followed leads to quite a lot of species which are only to be distinguished by the genitalia.

The practical value, therefore, of the hypopygium for determination may be considered as generally acknowledged. The theoretical importance, however, of the contrast between the considerable variability of the „other" specific characters, as shown above, and the constancy of the hypopygium, is not sufficiently appreciated. This constancy is the more striking according as another phenomenon is the more conspicuous, i.e., the dissimilarity of the various hypopygia within one genus. But, before we enter on this, something must be said about the relationships between the genera in so far as they become apparent from a study of the genitalia.

Comparing the figures of a series of hypopygia from different genera we are struck with the extraordinary disparity between species belonging to one and the same family. That Bolitophila is very different from Sciophila, Boletina, and Exechia is not so very strange, but we find this difference within the subfamilies too. 'Compare, e.g., Exechia, Rhymosia, Allodia, Phronia, and Fungivora. The differences are so conspicuous as never to leave any doubt about the generic identity of the hypopygium examined.

Still, the dissimilarity would not be of such importance, were it nci continued within the genera. The various genera of the Fungivorinae, to which subfamily our considerations will be limited, are, however, not equal in this respect.

In the genus Exechia we meet with such a diversiny that, generally, the species can be identified by mere examination of the hypopygium. Still, there are several species showing some similarity in the shape of this organ. Such is the case in the group: parva Lundstr. - repanda Joh. - capillata Joh. (See my paper cited above). Ancther instance is provided by spinigera Winn. - spinuligera Lundsir. - frigida Holmgr.

The Rhymosia species of the palaearctic region differ so much that groups such as the above mentioned cannot be formed.

In Allodia, on the contrary, we find several series of species with a very similar hypopygium. In this special case the characters necessary for separation of the species can be obtained only by careful dissection of the genitalia and a closc examination of details. In this way Edwards has been able to distinguish a number of species formerly unrecognizable.

Nor in Polyxena are the differences always very clear, but this may partly bc due to the simple structure of the male genitalia in this genus.

The latter is certainly not the case with Phronia, the hypopygium in this genus being of a very complicated shape, as described and depicted by Dziedzicky as early as 1889 . The difference between the various species is here most obvious and therefore determination would be very easy but for the difficulty in portraying these complex structures.

Finally Fungivora itself. Generally, in this genus also, we meet with a rich 
diversity of shape, making, on the whole, determination of the males rather easy. There are, however, a few species, constituting a well circumscribed group, in which the hypopygium shows only slight differences. These are: signata Meig., signatoides Dzied., and sigillata Dzied. Moreover, these species have still another character in common, viz., a very conspicuous yellow line along the middle of the foremost abdominal tergites.

A siudy of the hypopygium in other families of nematocerous Diptera will show us that great differences of shape in species considered to belong to one family, on the whole, do not exist. This is very clear in the family of the nonbiting midges or Tendipedidae. In this family the mere quantitative nature of specific differences generally is obvious, the tips of the claspers being more rounded or more pointed, the bristles being more numerous or scarcer, etc., without the general appearance being markedly influenced by these divergences.

$\mathrm{Sr}_{\mathrm{i}}$, in this respect there exists an undeniable difference between these two families. We might express it in this way, namely that, taking the hypopygia for a standard, the family of the fungus gnats consists of a comparatively small number of clearly defined species, while the other family contains a much larger number of less clearly defined species.

In my opinion such a difference between two families constitutes a problem in itself. First it can be interpreted as the result of a difference in the state of our knowledge of the two families in question. After all, the Fungivoridae arc one of the least studied of the large nematocerous families. From this point of view the explanation of the problem is to be expected from a new and more detailed examination of the fungus gnats, which might reveal new characters whereby the present species could be divided into a series of new ones.

It is, however, not at all improbable that the species we know at present are good species indeed, representing those systematical lower units to which, according to our modern views, reality must be assigned. In this case, in my opinion the more probable one, we have a family here, in which the species formation has come to a stop long ago.

For, the existence of such clearly defined species can be ascribed generally to two causes only: either in the region studied the family reaches the boundary of its distribution, or it is an old group, whose intermediate forms have disappeared in the course of time. Still, we must allow for a third possibility, for it may be that the specialized breeding habits in some degree hinder species formation. But to judge this possibility we ought to know more about the influence of environment on evolution than we actually do!

First of all, however, we are obliged to inquire whether the sharp delimitation of the species mentioned above does really exist. This is a problem in itself and to draw attention to it was the main purpose of the present paper. 